\title{
DINAMIKA HUBUNGAN ISLAM DAN LOKALITAS: PEREBUTAN MAKNA KEISLAMAN DI MADURA
}

\author{
Ahmad Zainul Hamdi \\ Universitas Islam Negeri Sunan Ampel Surabaya, Indonesia \\ E-mail: ahmadinung@gmail.com
}

\begin{abstract}
The discussion about Islam and local culture has resulted in a number of monumental academic works. The relation of Islam and the Javanese culture along with its dynamics have frequently colored intellectual debates in the field. Among the din of such fascinating academic debates, Islam Madura has been nearly neglected as an uninteresting academic discourse to observe. It has been argued that Madura is viewed as a "back door" of Java. It implies that observing Java means observing Madura automatically. This study seeks to raise the issue of contestation over the meaning of Islam within the relational context between Islam and the local culture of Madura society. Based on field research conducted under the light of Beatty's multi-vocality concept, the study finds that Islam Madura is a communal identity, but it defines nothing about the Madurese Muslim community in general. Although each group acknowledges Islam as a shared identity, every individual and group, or subgroup, will have no a common understanding about the meaning of Islam. Islam has, certainly, unified all the Madurese people within a common perspective of mankind, God, and worldly matters, but this identity represents no one and does not specifically define any conception of anyone. The meaning of Islam Madura has been, therefore, endlessly knitted within compromising and synthesis process.
\end{abstract}

Keywords: Local culture; syncretism; multi-vocality; interplay.

\section{Pendahuluan}

Membicarakan Madura tanpa membicarakan Islam sama halnya mengingkari fakta sosiologis tentang masyarakat Madura. Pandangan hidup orang Madura tidak bisa dilepaskan dari nilai-nilai agama Islam. ${ }^{1}$

1 A. Latif Wiyata, Mencari Madura (Jakarta: Bidik Phronesis, 2013), 3; Andang Subaharianto, et al., Tantangan Industrialisasi Madura (Malang: Bayumedia, 2004), 51. 
Sekalipun demikian, Islam Madura tampaknya bukan topik yang menarik bagi kalangan akademisi. Sejak Geertz melakukan studinya tentang agama Jawa di akhir tahun 1950-an, ${ }^{2}$ beberapa akademisi mulai melakukan berbagai riset tentang hubungan Islam dan tradisi lokal. Sayangnya, studi-studi tentang kaitan antara Islam dengan lokalitas di Indonesia yang telah melahirkan karya-karya antropologis monumental bisa dikatakan selalu mengabaikan Madura. Islam dan budaya lokal di Jawa sendiri telah melahirkan Clifford Geertz dengan Religion of Java, Mark R. Woodward dengan Islam Jawa, ${ }^{3}$ Andrew Beatty dengan Varieties of Javanese Religion, ${ }^{4}$ Robert W. Hefner dengan Tengger Tradition and Islam, ${ }^{5}$ dan berbagai karya lain yang cukup prestisius di dunia akademik internasional.

Tentu saja telah ada Huub de Jonge dan Iik Arifin Mansurnoor yang memberi informasi berharga tentang Islam di Madura. Akan tetapi, di antara dua karya yang menonjol itu, hanya karya Mansurnoor-lah yang sungguh-sungguh bisa disebut sebagai sebuah riset yang mengungkap secara serius Islam Madura melalui peran yang dimainkan ulama dalam konteks dinamika pembangunan Indonesia modern. ${ }^{6}$ Setelah itu, belum muncul lagi hasil riset yang memadai tentang dinamika Islam di Madura.

Bahkan sesungguhnya, sampai akhir tahun 70-an, Madura masih dianggap sebagai wilayah gelap yang belum dieksplorasi secara proporsional melalui studi-studi akademik yang mumpuni. Kajian tentang Madura dan orang Madura dianggap masih sangat minim. Ketika pada tahun 1995, A. Latief Wiyata melakukan penelitian tentang carok, ${ }^{7}$ sebuah budaya kekerasan khas Madura yang sudah

2 Clifford Geertz, The Religion of Java (Chicago dan London: The University of Chicago Press, 1960).

3 Mark R. Woodward, Islam Jawa: Kesaleban Normatif versus Kebatinan, terj. Hairus Salim HS (Yogyakarta: LKiS, 2004).

4 Andrew Beatty, Variasi Agama Jawa: Suatu Pendekatan Antropologi, terj. Achmad Fedyani Saefuddin (Jakarta: Murai Kencana, 2001).

5 Robert W. Hefner, Hindu Javanese: Tengger Tradition and Islam (Princeton, New Jersey: Princeton University Press, 1985).

${ }_{6}$ Lihat Iik Arifin Mansurnoor, Islam in an Indonesian World: Ulama of Madura (Yogyakarta: Gadjah Mada University Press, 1990); Anke Niehof, Women and Fertility in Madura (Leiden: t.tp., 1985), 4-5.

7 A. Latief Wiyata, Carok: Konflik Kekerasan dan Harga Diri Orang Madura (Yogyakarta: LKiS, 2006). 
sangat dikenal, pun de Jonge menilai itu sebagai kajian empiris pertama tentang topik tersebut. ${ }^{8}$

Tulisan Mansurnoor jelas telah menjadi sumber bacaan penting tentang Islam di Pamekasan, salah satu kabupaten di Pulau Madura. Karya Mansurnoor telah berhasil menghadirkan satu keislaman khas Madura dengan Pamekasan sebagai setingnya tentang ketaatan umat terhadap kiai, peran sosial-keagamaan kiai, dan jaringan-jaringannya dalam bernegosiasi dengan agen-agen modernisasi yang dalam beberapa hal dianggap mengancam posisi sosial kiai di tengah masyarakat.

Sekalipun demikian, di antara beberapa karya akademik yang sudah ada, sejauh ini belum ada yang secara sungguh-sungguh mencoba merekonstruksi hubungan antara Islam dengan budaya lokal Madura. Studi ini hendak membicarakan Islam dalam hubungannya dengan kultur Madura. Penulis berargumen bahwa tidak ada satu pun ajaran, termasuk agama, yang tumbuh di luar konteks di mana dia berada. Sebagai bagian dari kesadaran manusia, agama selalu berhimpitan dengan budaya di mana dia berada. Hubungan dinamis ini pada akhirnya harus meletakkan manusia sebagai subjek budaya aktif. Tidak ada satu pun masyarakat yang menjadi spon pasif yang menyerap setiap kebudayaan yang datang. Relasi aktif dalam pertemuan dua budaya inilah yang membuat studi-studi yang menyoroti hubungan antara Islam dengan budaya lokal selalu menarik untuk dikaji.

\section{Geografi, Demografi, dan Lapisan Dasar Kebudayaan Madura}

Kepulauan Madura merupakan gugusan dari sekitar tujuh pulau. Nama Madura dipinjam dari pulau terbesar. Pulau Madura terletak di antara $6^{\circ} 52^{\prime}$ dan $7^{\circ} 15^{\prime}$ Lintang Selatan, dan di antara $112^{\circ} 40^{\prime}$ dan $114^{\circ} 07^{\prime}$ Bujur Timur. Luasnya mencapai $4497 \mathrm{~km}^{2}$, ditambah sekitar $1.000 \mathrm{~km}^{2}$ yang terbagi di antara pulau-pulau kecil yang berada di gugusan itu. ${ }^{9}$ Madura termasuk wilayah datar, di mana kedalaman selat

\footnotetext{
${ }^{8}$ Huub de Jonge, "Kata Pengantar", dalam A. Latief Wiyata, Carok: Konflik Kekerasan dan Harga Diri Orang Madura (Yogyakarta: LKiS, 2006), ix-xii.

${ }^{9}$ Helene Bouvier, Lebur! Seni Musik dan Pertunjukan dalam Masyarakat Madura, terj. Rahayu S. Hidayat dan Jean Couteau (Jakarta: Forum Jakarta-Paris, Ecole Francaise d'Extreme-Orient, Yayasan Asosiasi Tradisi Lisan, Yayasan Obor Indonesia, 2002), 21.
} 
Madura tak lebih dari 100 meter dan gunung tertingginya, Tembuku, tingginya hanya 471 meter. $^{10}$

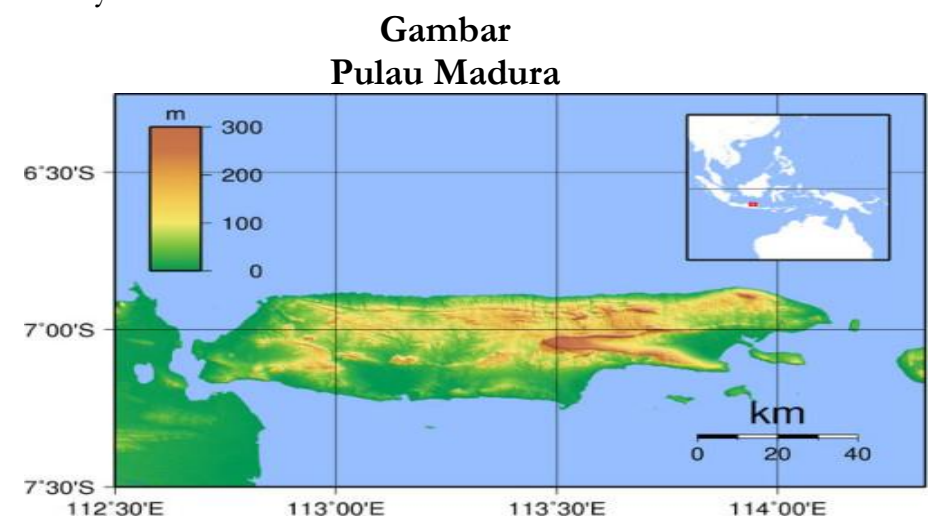

Berdasarkan sensus tahun 2000, jumlah etnis Madura di Indonesia sebanyak 6,7 juta jiwa dengan rata-rata pertumbuhan penduduk per tahun $0,65 \%$. Dari jumlah itu, tidak semua tercatat sebagai penduduk Madura. Tahun 1930, separuh lebih dari seluruh etnis Madura tinggal di Jawa, kebanyakan di bagian timur Jawa Timur. ${ }^{11}$ Tahun 2000, tercatat etnis Madura tersebar di 30 provinsi dengan Jawa Timur sebagai provinsi yang paling banyak dihuni oleh etnis Madura (6.281.058 jiwa) disusul oleh Kalimantan Tengah (203.612 jiwa). ${ }^{12}$ Sementara, berdasarkan sensus tahun 2010, jumlah orang yang tercatat sebagai penduduk Madura hanya berjumlah 2.622.763 jiwa.

\section{Tabel}

Jumlah Penduduk Madura Hasil Sensus Penduduk 2010

\begin{tabular}{|c|l|l|}
\hline No & Kabupaten & Jumlah \\
\hline 1 & Bangkalan & 906.761 \\
\hline 2 & Pamekasan & 795.918 \\
\hline 3 & Sampang & 877.772 \\
\hline 4 & Sumenep & 1.042 .312 \\
\hline JUMLAH & 2.622 .763 \\
\hline
\end{tabular}

Sumber: Jawa Timur dalam Angka 2013,

Badan Pusat Statistik Provinsi Jawa Timur

10 Kuntowijoyo, Perubahan Sosial dalam Masyarakat Agraris Madura 1850-1940 (Yogyakarta: Mata Bangsa, 2002), 26.

${ }^{11}$ Ibid., 80.

12 Leo Suryadinata, dkk., Penduduk Indonesia: Etnis dan Agama dalam Era Perubahan Politik (Jakarta: LP3ES, 2003), 46-48. 
Menurut Lombard, orang Madura dan orang Jawa berada dalam satu komunitas budaya yang sama. ${ }^{13}$ Penilaian Lombard tersebut merujuk pada lapisan dalam kejiwaan yang membentuk unsur-unsur keyakinan orang Jawa dan Madura. Sebelum periode Islam, penduduk Jawa dan Madura memiliki tradisi dan keyakinan lokal yang kurang lebih sama. ${ }^{14}$ Asumsi ini bisa dibenarkan jika kita mempertimbangkan bahwa pada dasarnya penduduk Asia Tenggara memiliki pandangan batin yang sama, atau apa yang disebut Niels Mulder sebagai agama Asia Tenggara. ${ }^{15}$

Secara ringkas, sifat agama Asia Tenggara adalah samarnya batas antara yang sakral dan profan. Agama bagi penduduk Asia Tenggara adalah sebuah keterpesonaan terhadap rahasia hidup dalam segala perwujudannya. Dalam keterpesonaan ini, praktik-praktik keagamaan selalu terkait dengan keyakinan animistik, kekuatan dan kekuasaan yang ada pada alam (nature) dan alam adikodrati (supernature) yang mengelilingi manusia. Kekuatan dan kekuasaan itu ada pada makhlukmakhluk ilahi, orang-orang suci, roh-roh, orang-orang yang sudah meninggal, benda-benda keramat, yang semua itu menjadi bagian dari situasi alamiah dan kehidupan sehari-hari. Kekuatan dan kekuasaan itu dekat, dapat dirasakan, dapat diperoleh, dapat diminta, bahkan dimanipulasi. Karena itu, dibutuhkan pengetahuan tentang tata cara untuk berhubungan dengannya. Praktik-praktik keagamaan, seperti asketisme dan meditasi, adalah bagian dari cara untuk meningkatkan potensi seseorang dalam kaitannya dengan kekuatan atau kekuasaan itu. Ada juga upacara-upacara yang khusus dilakukan untuk memperalat atau membujuk kekuatan itu untuk memberi perlindungan atau keselamatan. Ada juga yang berhubungan dengan kekuatan itu secara magis untuk tujuan-tujuan penyembuhan. Perewangan-perewangan digunakan sebagai agen yang menjembatani antara dunia yang tak kelihatan dengan dunia nyata sehari-hari. Praktik ini terlihat dalam perdukunan, keampuhan jimat, upacara persembahan, atau berbagai bentuk riadat (matiraga). Dalam masyarakat Asia Tenggara, praktik-praktik magis tidak pernah dianggap sebagai sesuatu yang tidak bermoral atau berdosa, tapi itu

\footnotetext{
${ }^{13}$ Denys Lombard, Nusa Jawa: Silang Budaya, Vol. 2 (Jakarta: Gramedia, 1996).

${ }^{14}$ Mansurnoor, Islam in an Indonesian World, 7.

15 Niels Mulder, Agama, Hidup Sehari-hari, dan Perubahan Budaya, terj. Satrio Widiatmoko (Jakarta: Gramedia, 1999), 10.
} 
hanyalah sebuah cara berhubungan dan memanipulasi kekuatan dan kekuasaan alam atau adikodrati itu. ${ }^{16}$

Sebegitu vitalnya kekuatan atau kekuasaan adikodrati ini, sampai Mulder mengatakan bahwa locus terpenting dari agama Asia Tenggara adalah perasaan dan keakraban seseorang secara pribadi dengan kekuatan atau kekuasaan yang tak kelihatan itu. Matiraga untuk mencari petunjuk ilahi yang bersifat langsung adalah wujud dari keakraban terhadap kesaktian (energi kosmis), terhadap roh-roh, di samping kehendak untuk menjumpai kekuatan dan kekuasaan itu dengan hati. Berbagai praktik keagamaan lain selalu berkaitan dengan kerinduan dan pencarian akan keamanan dan keterjaminan hidup dengan mengandalkan diri pada sumber-sumber kekuatan adikodrati. Itu juga menandakan keyakinan terhadap penyelenggaraan dan pemeliharaan yang bersifat adikodrati. ${ }^{17}$

Agama Asia Tenggara bersifat fungsional dalam hidup manusia saat ini dan di sini. Agama berfungsi untuk menjamin kehidupan yang penuh selamat dan terberkati. Praktik keagamaan Asia Tenggara menekankan pada fungsinya untuk menjamin keselamatan dan berkat perlindungan supaya jauh dari bahaya dan kemalangan. Hal-hal yang terkait dengan konsep-konsep kesaktian adalah untuk memastikan keberlangsungan eksistensi duniawi, seperti keselamatan dan kemakmuran. Dosa tidak terkait dengan perintah-perintah abstrak dari dewa yang maha tinggi dan unik, namun terkait dengan penjagaan keseimbangan dalam kehidupan bersama saat ini. ${ }^{18}$

Rasa, ilham, "wahyu", dan intuisi menempati posisi tinggi daripada pemikiran dogmatis. Keyakinan kepada Tuhan adalah sesuatu yang sepenuhnya bersifat pribadi. Yang dituntut dalam kehidupan bermasyarakat adalah penghormatan terhadap tata keteraturan masyarakat. Inilah cara hidup yang bermoral. Misalnya, orang Jawa meyakini, "Orang yang menghormati orang tuanya, kakaknya, gurunya, dan rajanya, menghormati Allah". Pesan yang hendak disampaikan adalah kewajiban untuk menghormati keteraturan masyarakat yang bersifat hierarkis. Orang yang bermoral adalah sejauh ia mampu melaksanakan kewajibannya dalam hubungannya dengan orang lain. Moralitas di sini lebih bersifat sosial daripada keagamaan. Ini akhirnya membentuk suatu sikap keagamaan

\footnotetext{
${ }^{16}$ Ibid., 11-12.

${ }^{17}$ Ibid., 14-15.

18 Ibid., 17.
} 
yang menekankan pada toleransi, kesabaran, kompromi, menghindari pertentangan, dan penghormatan terhadap perasaan pribadi-pribadi. ${ }^{19}$

Apa yang disebut sebagai agama Asia Tenggara tersebut seperti sebuah master yang perwujudannya bisa dijumpai di wilayah Nusantara dengan berbagai variasi yang terbentuk karena perbedaan lokalitas. Orang Jawa, misalnya, meyakini bahwa kehidupan manusia adalah bagian sepenuhnya dari totalitas kosmos. Ketidakseimbangan kosmos akan menyebabkan penderitaan manusia. Di samping itu, di alam semesta ini ada kekuatan yang melebihi dari yang lain, yang disebut kesaktian. Kekuatan ini, bersama dengan kekuatan lain, semisal arwah leluhur dan makhluk-makhluk halus lain, ada di sekitar mereka dan memengaruhi kehidupan mereka. Kekuatan itu bisa dimintai atau dimanipulasi untuk kepentingan manusia. Karena itu, maka perlu upacara tertentu untuk menghubungkan manusia dengan kekuatankekuatan tersebut agar keselarasan kosmos tetap terjaga. Ritual itu adalah slametan. ${ }^{20}$

Geertz menyatakan bahwa seluruh sistem keyakinan Jawa memusat pada praktik slametan yang menyimbolkan kesatuan mistik dan sosial. Dalam slametan, yang terlibat tidak hanya orang-orang yang diundang untuk hadir, tapi juga makhluk-makhluk penunggu atau penjaga kampung, roh-roh orang yang sudah meninggal dunia, dan kekuatan supranatural lain. Mereka semua berkumpul membentuk sebuah kesatuan yang saling mendukung dan bekerja sama. Slametan membentuk sebuah kerjasama universal yang selaras dalam rangka mencapai slamet, yaitu terhindar dari ketidakpastian, ketegangan dan konflik. ${ }^{21}$

Ritual slametan ini menjadi bagian penting praktik keagamaan populer orang Madura. Slametan di Madura disebut dengan istilah rokat (ruwat dalam istilah Jawa). Penelitian Roy Edward Jordaan menunjukkan bahwa kemalangan yang diterima oleh orang Madura diyakini terkait dengan kekuatan-kekuatan kosmologis dan supranatural. Menjaga hubungan baik dengan kekuatn-kekuatan itu

\footnotetext{
${ }^{19}$ Ibid., 10-14.

${ }^{20}$ Lihat Kodiran, "Kebudayaan Jawa", dalam Koentjaraningrat (ed.), Manusia dan Kebudayaan di Indonesia (Jakarta: Djambatan 2007), 347.

${ }^{21}$ Geertz, The Religion of Java, 11. Untuk informasi lain tentang keyakinan dan praktik keagamaan orang Jawa, lihat M. Soehadha, Orang Jawa Memaknai Agama (Yogyakarta: Kreasi Wacana, 2008); John Pemberton, Jawa, terj. Hartono Hadikusumo (Yogyakarta: Mata Bangsa, 2003); Robert W. Hefner, Hindu Javanese (Princeton, New Jersey: Princeton University Press, 1985).
} 
adalah keharusan agar terhindar dari kemalangan. Itulah mengapa diperlukan ritual tertentu, tujuannya adalah untuk menjaga agar kehidupan tidak berada dalam situasi yang berbahaya. ${ }^{22}$

Sama halnya slametan di Jawa, rokat di masyarakat Madura pada dasarnya adalah ritual untuk menghindarkan seseorang dari marabahaya. Rokat dilaksanakan untuk menghindari bencana alam atau sakit. Rokat secara umum adalah cara untuk menghindar dari kemalangan yang mungkin saja datang di luar pertimbangan manusia. Pindah ke rumah baru tanpa melakukan rokat, misalnya, sama halnya dengan membiarkan masalah yang ada di depan mata bisa datang sewaktu-waktu tanpa kita tahu. Rokat bisa dilaksanakan secara individual maupun sosial. Rokat yang merupakan aktivitas sosial adalah rokat yang menyangkut keselamatan bersama. Rokat ini misalnya rokat tase' dan rokat bumeh. Rokat yang pertama merupakan ritual tahunan bagi nelayan yang menandai musim untuk mencari ikan di laut, sedang yang terakhir terkait dengan ritual panen bagi petani di desa-desa Madura. Tujuannya adalah meminta keselamatan dan berkah kepada kekuatan penguasa laut dan dayang penjaga desa. ${ }^{23}$ Ritual ini jelas memperlihatkan kesamaannya secara umum dengan keyakinan lokal masyarakat-masyarakat Asia Tenggara.

Di balik praktik rokat, bersemayam sebuah sistem keyakinan terhadap kekuatan-kekuatan supranatural, yang jahat maupun yang baik. Kehidupan manusia sesungguhnya tidak bisa dilepaskan dari kekuatan-kekuatan tersebut, karenanya diperlukan sebuah ritual, termasuk di dalamnya adalah keyakinan tentang waktu dan tempat keramat, dalam rangka untuk membangun komunikasi dan menjaga hubungan dengan kekuatan-kekuatan tersebut. Kekuatan-kekuatan ini hadir dan berbagi tempat dengan kita. Untuk memastikan keselamatan dan kesejahteraan hidupnya, orang Madura meyakini bahwa makhlukmakhluk ini harus dijinakkan melalui ritual-ritual tertentu. Dalam menjalankan ritual ini, diperlukan orang yang memiliki kekuatan magis (kadigdajan atau kasaktian) yang bisa melakukan komunikasi dengan makhluk-makhluk tersebut. ${ }^{24}$

22 Roy Edward Jordaan, Folk Medicine in Madura (Indonesia) (Leiden: Leiden University, 1985), 65.

${ }^{23}$ Ibid., 65-73.

${ }^{24}$ Mansurnoor menyatakan bahwa makhluk-makhluk ini hanyalah berfungsi sebagai perantara (se areksa) antara manusia dengan kekuasaan yang lebih tinggi. Namun sejauh meletakkan agama populer Madura ke dalam indigenous religion penduduk Asia Tenggara, maka sesungguhnya tidak bisa dibedakan antara makhluk gaib dan dewa- 
Kepada penduduk dengan keyakinan seperti inilah Islam masuk ke wilayah Madura. Yang membedakan Islamisasi di Jawa dan di Madura adalah bahwa ketika Islam masuk ke Jawa, ia berjumpa dengan penduduk lokal (dengan indigenous beliefs-nya) yang telah tertransformasi ke dalam agama Hindu-Buddha. ${ }^{25}$ Sementara di Madura, tidak ada satu pun bukti yang menunjukkan bahwa agama Hindu-Buddha pernah menjadi agama rakyat sekalipun tidak diragukan bahwa para penguasa politik lokal adalah pengikut agama Hindu atau Buddha terkait dengan hubungannya kepada kerajaan Hindu-Buddha di Jawa. Keyakinan dan tradisi yang dipeluk oleh para bangsawan hanya terbatas di istana. Sebagaimana yang dinyatakan Mansurnoor, ...indigenous Madurese belief system was more prevalent than any other tradition in the history of Madura. ${ }^{26}$

Jika ada pertanyaan, mengapa Hindu-Buddha tidak pernah menjadi agama yang begitu kuat dipeluk oleh rakyat Madura sebagaimana di Jawa. Tidak diragukan bahwa penduduk Madura juga

dewa. Lagi pula, pemikiran filosofis dan sophisticated tentang masalah-masalah eskatologis bukanlah tipikal agama populer penduduk Asia Tenggara. Yang menjadi inti dari keyakinan dan praktik keagamaan penduduk Asia Tenggara adalah fungsi agama dalam kehidupan riil. Mereka memang mengakui ada makhluk-makhluk gaib yang baik dan yang jahat, namun pada akhirnya semua itu harus dipastikan tidak mengganggu kehidupan manusia di dunia, baik melalui ritual maupun sesaji. Mansurnoor, Islam in an Indonesian World, 3-4.

25 Situs-situs agama Buddha dan Hindu (Shiwais) di Jawa selalu terkait dengan lingkaran elit keraton. Ini bisa memunculkan pemikiran lain bahwa selama ini Buddha dan Hindu sebagai sebuah sistem keagamaan yang koheren hanya sungguhsungguh hidup di keraton daripada di kalangat rakyat kebanyakan. Para pendeta menjadi bagian dari pemerintahan kerajaan. Keberadaan candi-candi yang dijadikan tempat peribadatan selalu terhubung dengan keraton. Penting untuk mempertimbangkan catatan Vlekke, “...keputusan menganut Budhisme atau Shiwaisme adalah urusan para raja dan bahwa masuknya satu agama baru tidak menimbulkan perubahan mendasar dalam praktik pemujaan populer, walau mungkin ada tambahan unsur-unsur baru. Juga tidak ada tuntutan terhadap rakyat banyak untuk menganut ajaran Buddha atau secara eksklusif menyembah dewadewa Shiwais". Baca Bernard H. M. Vlekke, Nusantara Sejarah Indonesia, terj. Samsudin Berlian (Jakarta: Gramedia dan Freedom Institute, 2008), 41. Dengan cara berpikir seperti ini, kita bisa memahami perbedaan varian abangan dan priyayi dalam tipologi Geertz tentang Islam Jawa. Varian abangan merujuk pada para petani atau rakyat kebanyakan yang tetap terikat dengan local belief-nya yang bersifat animistik, sedang priyayi mengembangkan budaya dan praktik-praktik spiritualitas yang bersumber dari ajaran-ajaran Buddha-Hindu. Lihat Geertz, The Religion of Java, 6-7.

26 "Sistem kepercayaan asli Madura sangat mendominasi dalam sejarah Madura". Mansurnoor, Islam in an Indonesian World, 7. 
menyerap keyakinan-keyakinan Indik yang datang dari luar, terutama Jawa. Namun ketiadaan tempat-tempat pendidikan agama HinduBuddha yang digawangi oleh para resi sebagaimana di Jawa membuat penduduk Madura hanya menjadikan keyakinan-keyakinan Indik sebagai bagian dari keyakinan lokalnya. Tidak adanya situs-situs Hindu-Buddha juga menandakan bahwa tidak adanya upaya dari keraton Madura menginstitusionalisasi agama Hindu-Buddha secara intens. Karena itu, keyakinan Hindu-Buddha hanya dipeluk dan dipraktikkan dalam lingkungan elit keraton, sementara penduduk lokal mengadopsinya sebagai bagian dari keyakinan lokal. Sejauh tidak ada konsekuensi apapun dari keraton, tidak ada kepentingan apapun untuk mengidentifikasi dirinya secara formal dengan agama yang dibawa oleh para rato-nya.

\section{Islam Masuk ke Madura}

Susah untuk menyangkal bahwa Islam masuk ke Madura berasal dari Jawa. Ada sebagian kecil yang menyatakan bahwa Islam yang berada di wilayah timur pulau ini bisa jadi tidak berasal dari Jawa, tapi dari wilayah Kalimantan atau Sulawesi atau Lombok. Jika pendapat ini bertendensi untuk menghapus jejak Jawa dalam perkembangan Islam Madura, maka pendapat ini akan sia-sia. Sejak dulu, wilayah Sumenep, bagian paling timur Madura, memiliki hubungan yang lebih dekat dengan Jawa daripada luar Jawa, sebuah hubungan yang tetap bertahan sampai ketika Jawa berada di bawah kekuasaan kesultanan Islam. Di samping itu, jalur laut antara Madura dan Jawa lebih utama daripada pelayaran ke wilayah utara dan timur. Migrasi terbesar dari penduduk Madura wilayah timur adalah Jawa, terutama Jawa Timur.

Jika pendapat ini bertendensi untuk melepaskan Madura dari corak keislaman Jawa yang bersifat Indik, maka yang perlu diperhatikan adalah tidak ditemukan adanya perbedaan corak keislamaan antara Madura barat dan timur. Di samping itu, jika pun Islam yang masuk dan berkembang di Madura timur berasal dari wilayah Kalimantan atau dari arah timur lain, maka upaya puritanisasi sejarah Islam Madura juga akan sia-sia. Ketika Islam masuk ke wilayah Banjarmasin, misalnya, yang ditemui adalah berbagai peninggalan dari masa Majapahit yang berciri Hindu Jawa. Sejak abad ke-13, Kalimantan hingga berbagai pulau di sebelah timur Jawa, seperti Kepulauan Nusa Tenggara Barat, Sulawesi, dan Maluku, berada di 
bawah kekuasaan kerajaan Hindu-Buddha Jawa. Yang juga perlu dicatat adalah bahwa Makassar baru disentuh Islam pada abad ke-17. ${ }^{27}$

Yang tidak kalah penting untuk dipertimbangkan adalah peran Walisongo, para penyebar Islam penting di Jawa, dalam penyebaran Islam di pulau-pulau luar Jawa. Sejarah Islam di Mataram, misalnya, sangat terkait dengan ekspansi kesultanan Islam Jawa pasca-runtuhnya Kerajaan Majapahit. ${ }^{28}$ Sunan Giri memainkan peranan penting dalam penyebaran Islam di wilayah timur Jawa hingga ke pulau-pulau luar. ${ }^{29}$ Sekolah keagamaannya di bukit Giri, yang langsung bisa melihat keindahan selat Madura, didatangi murid hingga dari wilayah Maluku. ${ }^{30}$ Trunajaya adalah salah seorang santri Giri di bawah asuhan Sunan Prapen. Pangeran Bugan dari Sumenep beberapa tahun menghabiskan waktu studinya di Cirebon dan kemudian dilanjutkan nyantri di Giri. Keluarga Batuampar Pamekasan mengklaim dirinya sebagai keturunan ulama terkenal dari Jawa Barat, al-Anggawi. ${ }^{31}$ Ketika Demak mulai membangun kekuasaannya, wilayah Tanjung Pura (Bangka dan Belitung) termasuk salah satu wilayah yang berada di bawah pengaruhnya. ${ }^{32}$ Giri memainkan peran sangat penting dalam pengislaman Jawa Timur dan beberapa kantong dagang di luar Jawa, di pantai Kalimantan dan terutama di Kepulauan Maluku. Raja-raja Madura bagian barat masuk agama Islam karena pengaruh Giri. ${ }^{33}$

Mempertimbangkan berbagai data itu, sangat beralasan untuk melihat sejarah masuk dan berkembangnya Islam di Madura dengan melacaknya dari dinamika perkembangan Islam di Jawa, terutama di pesisir pantai utara Jawa. Ini adalah sebuah tempat di mana Islam pertama kali memasuki pulau Jawa. Ia juga sebuah tempat yang berkembang menjadi kota-kota metropolis tempat bertemunya beragam manusia dari berbagai penjuru.

Sejarah masuknya Islam ke Madura kurang lebih memperlihatkan skema yang melibatkan jaringan pelayaran dan niaga laut, pendakwah profesional, dan peran keraton. Jelas, orang Madura, terutama yang ada di wilayah pesisir, terlibat dalam jaringan laut, baik sebagai nelayan

\footnotetext{
${ }^{27}$ Lombard, Nusa Jawa, Vol. 2, 35, 40, 44, dan 125.

${ }^{28}$ Erni Budiwanti, Islam Sasak (Yogyakarta: LKiS, 2000), 9.

${ }^{29}$ Tentang peran sentral yang dimainkan Giri dalam masalah politik dan agama, lihat H.J. De Graff, Puncak Kekuasaan Mataram (Jakarta: Grafiti, 2002), 246-250.

${ }^{30}$ Lombard, Nusa Jawa, Vol. 2, 42.

${ }^{31}$ Mansurnoor, Islam in an Indonesian World, 25.

${ }^{32}$ Lombard, Nusa Jawa, Vol. 2, 44.

${ }^{33}$ Ibid., 56.
} 
maupun pebisnis antarpulau. Bagaimanapun juga, Madura termasuk wilayah pesisir di mana sejak dulu orang-orang Madura sudah berlayar ke luar pulaunya dan bersentuhan dengan para penduduk luar dengan seluruh budaya dan pandangan hidupnya. Keterlibatannya dalam lalu lintas perdagangan antarpulau memungkinkan mereka untuk bertemu dengan para pedagang pemeluk Islam yang jalur dagangnya terbentang mulai Malaka hingga laut utara Jawa. Bisa dikatakan bahwa Islam menyentuh penduduk Madura sedini Islam masuk Jawa sekalipun harus cepat dinyatakan bahwa proses Islamisasi masif baru sungguh-sungguh terjadi ketika keraton-keraton Madura terlibat dalam Islamisasi seiring dengan masuk Islamnya para ningrat Madura di paruh kedua abad ke-16. ${ }^{34}$

Sementara, kehadiran para pendakwah profesional sangat dikenal melalui berbagai cerita lisan. Misalnya, pendakwah Islam mula-mula di Sumenep dikenal dengan nama Sunan Padusan. Ia datang di awal abad ke-16. Dia diklaim sebagai keturunan Maulana Malik Ibrahim, pendakwah Islam mula-mula di wilayah pantai utara Jawa, yang membangun perkampungan Islam di pesisir Gresik. ${ }^{35}$ Cerita Modin Teja juga sangat dikenal di Pamekasan. Nama Teja diambil dari wilayah di mana dia menetap dan melakukan aktivitas dakwahnya. Nama aslinya adalah Abdullah. Ia datang saat keraton masih memegang teguh ajaran Budha. Di Teja, dia tidak hanya mengajarkan Islam, tapi juga membangun irigasi sederhana yang dimanfaatkan oleh para petani di sekitarnya. Dia berhasil mengajak orang-orang di sekitarnya memeluk Islam. Dia gagal mengislamkan keluarga keraton Pamekasan, tugas yang kemudian sukses dilanjutkan oleh menantunya, Abdurrahman. Abdurrahman dikirim untuk belajar Islam pada seorang ulama di Sampang. Setelah menyelesaikan pendidikannya, santri Abdurrahman tidak kembali ke Teja tapi melanjutkan dakwah Islam dengan metode yang kurang lebih sama, di daerah selatan. Di tempat barunya, dia berhasil membangun pertanian, keberhasilan yang membuat sang rato tertarik. Dari sini kemudian terjalin kontak dengan keraton yang pada akhirnya membuat sang rato memeluk Islam. Para santri yang telah menyelesaikan pendidikannya kemudian menjadi agen penyebar Islam di desanya masing-masing. Sementara santri-santri istimewa mendapat

\footnotetext{
34 Azyumardi Azra, Jaringan Ulama Timur Tengab dan Kepulauan Nusantara Abad XVII dan XVIII (Jakarta: Kencana, 2013), 8.

35 Mansurnoor, Islam in an Indonesian World, 21.
} 
mandat khusus untuk melakukan dakwah di tempat-tempat tertentu. Misalnya, Bungso, murid istimewa Abdurrahman, diminta untuk mendirikan pesantren di wilayah Sumenep. ${ }^{36}$

Di wilayah Madura barat, ada kisah tentang Ratu Ranggasukawati yang bermimpi tentang seorang wali yang bertapa di bawah sebuah pohon besar di sebelah selatan wilayah kerajaannya. Dikisahkan banyak orang-orang yang berguru kepadanya. Dia adalah seorang santri dari Kiai Gunungsari di Sampang. Karena aktivitas semedinya itu, kerajaan dilanda kekeringan selama berbulan-bulan. Tidak ada kata lain bagi sang rato kecuali harus menemui sang wali pertapa ini. Kisah ini menunjukkan adanya upaya pengislaman dengan menarik rakyat banyak yang pada akhirnya menarik perhatian sang rato. ${ }^{37}$

Istana memainkan peran signifikan dalam menyebarkan Islam di wilayah Madura. Silsilah kiai besar Madura selalu bersambung dengan keluarga keraton. Dalam konteks ini, peran Demak, Keraton Giri dan Ampel tidak bisa diabaikan. ${ }^{38}$ Bahkan, ketika Majapahit masih de jure berkuasa, Demak sudah mengirimkan wakilnya ke wilayah Madura timur. Salah seorang putri sultan Demak dinikahkan dengan Pangeran Pemadekan, Sampang. ${ }^{39}$ Ini menunjukkan adanya hubungan yang terbangun antara Demak dengan Madura, sebuah hubungan yang terbangun di akhir kekuasaan Majapahit saat Demak belum berdiri sebagai sebuah kerajaan yang independen.

Cerita lisan yang beredar di Arosbaya, Bangkalan, mengonfirmasi peran Demak ini. Sang pangeran, Pratanu, mengadu kepada ayahnya bahwa dia bermimpi bertemu Sunan Kudus dari Demak yang memintanya untuk memeluk Islam. Sang raja kemudian mengutus patihnya menemui Sunan Kudus di Demak. Setelah bertemu dan belajar Islam kepada Sunan Kudus, si patih memutuskan memeluk Islam. Ketika mau kembali ke Madura dengan cara berjalan di atas laut, dia tidak bisa lagi karena sudah kehilangan kekuatan magisnya setelah memutuskan masuk Islam. Sunan Kudus meyakinkan bahwa dia tetap bisa memiliki kekuatan yang sama dengan cara memohon pertolongan kepada Allah sebagai seorang Muslim. Untuk membuktikan ucapannya, Sunan Kudus kemudian menghanyutkan

\footnotetext{
36 Ibid., 9-14.

${ }^{37}$ Ibid., 22-23.

38 Azra, Jaringan Ulama, 11.

${ }^{39}$ Mansurnoor, Islam in an Indonesian World, 20.
} 
pelepah kelapa dan meminta si patih untuk naik di atasnya dan pulang ke Madura. ${ }^{40}$

Hubungan antara ulama dengan keraton bisa dilihat dalam kehadiran pangolo (penghulu) atau tokoh agama Islam di lingkungan keraton. Hubungan ini juga terjalin melalui pernikahan, misalnya pernikahan antara Bindara Saod, putra Kiai Bungso, dengan seorang putri dari keraton Sumenep. ${ }^{41}$ Dukungan keraton terhadap penyebaran Islam juga bisa dilihat dari adanya tanah perdikan yang diberikan kepada para tokoh agama. Tanah perdikan adalah sebuah wilayah otonom yang dikelola oleh orang yang dianugerahi oleh kerajaan. Di Sumenep, misalnya, desa Sendir, Batuampar dan Brangbang diserahkan kepada ulama sebagai tanah perdikan. ${ }^{42}$

\section{Islam Madura: Perebutan Makna}

Pertanyaan yang hendak dijawab di bagian akhir ini adalah bagaimana menjelaskan Islam (lokal) Madura: apakah ia Islam(i) ataukah tidak? Sebuah pertanyaan klasik yang sekian lama menjadi materi debat antara kalangan Muslim tradisionalis dan reformis, juga para ilmuwan yang mencoba menteoretisasikannya.

Penjelasan paling lumrah atas fenomena Islam lokal sebagaimana Islam Madura adalah menilainya sebagai sinkretis. ${ }^{43}$ Nama Geertz selalu menjadi rujukan utama bagi penjelasan versi ini. Dalam studinya tentang Islam Jawa, Geertz secara tegas menyatakan,

In the days before the Hindus, who began to come to the island around 400 A.D. or before, it seems likely that the sort of "animism" common still to many of the pagan tribes of Malaysia comprised the whole of the religious tradition; but this tradition has proved, over the course of the centuries, remarkably able to absorb into one syncretized whole elements from both Hinduism and Islamism, which followed it in the fifteenth century. Thus today the village religious system commonly consists of a balanced integration of

\footnotetext{
${ }^{40}$ Ibid., 23-24.

${ }^{41}$ Ibid., 15.

42 Ibid., 17.

43 Sinkretisme adalah upaya untuk menenggelamkan berbagai perbedaan dan menghasilkan kesatuan di antara berbagai sekte atau aliran filsafat. Dalam antropologi dan teologi modern, istilah sinkretisme paling sering dipakai untuk menggambarkan upaya memadukan berbagai unsur yang terdapat di dalam bermacam-macam keyakinan dalam masalah keagamaan, tanpa memecahkan berbagai perbedaan dasar dari prinsip-prinsip yang ada di dalamnya. Baca Mulder, Agama, Hidup Sehari-hari, 3.
} 
animistic, Hinduistic, and Islamic elements, a basic Javanese syncretism which is the island's true folk tradition.... ${ }^{44}$

Pandangan Geertz ini telah melahirkan banyak sekali kritik. Woodward adalah salah satu sarjana yang menolak pandangan Geertz karena tidak menemukan unsur-unsur Indik dalam Islam Jawa. Woodward menunjukkan bahwa Islam dan Jawa merupakan dua entitas yang saling melengkapi. Apa yang selama ini dianggap oleh Geertz sebagai varian-varian Islam dan non-Islam sesungguhnya adalah varian-varian internal Islam yang pertentangan di antara mereka merujuk pada pertentangan klasik dalam Islam, yaitu Islam yang berorientasi fiqh dan Islam yang berorientasi tasawuf, hukum dan mistik, wadah dan isi, lahir dan batin. Oleh karena itu, maka Islam Jawa atau Islam yang diartikulasikan dalam cita rasa Jawa, harus dipandang dengan hormat sebagaimana tidak pernah ada Islam yang tidak diartikulasikan dalam kerangka lokal di manapun dia berada. Dengan menunjuk praktik Islam di Yogyakarta, Woodward menegaskan bahwa Islam yang dianut masyarakat Jawa bisa mengambil bentuk yang berbeda-beda, dan itu semuanya adalah Islam. ${ }^{45}$

Muhaimin dan Pranowo adalah dua sarjana Muslim Indonesia yang memiliki persamaan pandangan dengan Woodward. Menurut Muhaimin, Islam Jawa secara esensial adalah Islam yang absah karena apapun wujud artikulasi lokalnya, ia tetap bersandar pada tiga fondasi: imān, Isläm, dan ihssān. Suatu tradisi bersifat Islami jika pelakunya bermaksud atau mengaku bahwa tingkah lakunya sesuai dengan jiwa Islam, sekalipun tetap harus memiliki sandaran normatifnya kepada teks suci. Tetapi, referensi terhadap kitab suci ini tidak mesti selalu dalam pola relasi langsung, bisa secara tidak langsung, bahkan mungkin tidak disadari. ${ }^{46}$ Sementara, Pranowo menyatakan bahwa Islam tidak pernah membangun relasi oposisional dengan tradisi Jawa.

\footnotetext{
44 "Pada masa sebelum Hindu datang ke Jawa sekitar tahun $400 \mathrm{M}$ atau sebelumnya, tampaknya animisme adalah keyakinan umum suku-suku pagan Malaysia. Setelah berabad-abad kemudian, tradisi ini membentuk sinkretisme dalam campuran Hindu dan Islam yang datang pada abad ke-15. Saat ini, sistem keagamaan desa secara umum terdiri atas integrasi yang seimbang antara elemen-elemen animisme, Hindu, dan Islam, sebuah sinkretisme Jawa yang menandai tradisi rakyatnya". Geertz, The Religion of Java, 5.

${ }^{45}$ Lihat Woodward, Islam Jawa.

46 Muhaimin AG., Islam dalam Bingkai Budaya Lokal: Potret dari Cirebon Jakarta: Logos, 2001), 12-15.
} 
Islam hadir di Jawa dan menjadi Islam Jawa sambil tetap memegang prinsip Islam sendiri. ${ }^{47}$

Di sini, seolah hendak dinyatakan bahwa Islam harus didefinisikan berdasarkan suara umat Islam sendiri sesuai dengan konteks budayanya masing-masing. Selalu terjadi dialektika yang dinamis antara Islam dalam kategori universal dengan lokalitas di mana dia hidup. Hal ini dikarenakan sekalipun Islam memiliki karakter universal, ia juga merupakan produk dari pergulatannya dengan lokalitas. Menurut Manger, There are as many Islam as there are situation that sustain them. ${ }^{48}$

Beberapa sarjana mengritik penggunaan sinkretisme bukan karena ketidaktepatannya, tapi karena tendensi perendahan yang melekat dalam dirinya. Di samping karena istilah itu tidak menambah pemahaman apapun sejauh ia merujuk pada percampuran dan perpaduan yang merupakan akibat umum dari persinggungan atau kontak kebudayaan. Atas dasar itulah Mulder lebih memilih untuk menggunakan istilah "lokalisasi".

Lokalisasi adalah sebuah konsep yang menjelaskan bahwa sebuah komunitas budaya yang menerima pengaruh dari luar akan menyerap dan menyatakan kembali unsur-unsur asing dengan cara menempa unsur-unsur asing itu sesuai dengan pandangan hidupnya. ${ }^{49}$ Dalam konteks keagamaan, konsep lokalisasi yang diperkenalkan Mulder sama dengan pandangan Eickelman bahwa ... any religion's ideology and practice are elaborated, understood and subsquently reproduced in particular places and at particular moments. ${ }^{50}$

Dengan cara pandang inilah Hefner menjelaskan tentang Hindu Jawa. Jika Hindu bagi banyak kalangan dianggap sebagai faktor dominan yang menentukan tradisi Jawa, maka pandangan tersebut hanya bisa dibenarkan dalam batasan-batasan tertentu. Menurut Hefner, Hindu memang memberi pengaruh kuat terhadap tradisi

\footnotetext{
${ }^{47}$ Lihat Bambang Pranowo, "Traditional Islam in Contemporary Rural Java", dalam M.C. Ricklefs (ed.), Islam in the Indonesian Social Context (Clayton, Victoria, Australia: Center of Southeast Asian Studies Monash University, 1991).

48 "Ada banyak Islam sebanyak situasi yang membentuknya". Leif Manger, "Muslim Diversity: Local Islam in Global Contexts", dalam Leif Manger (ed.), Muslim Diversity Local Islam in Global Contexts (Richmond: Curzon Press, 1999), 17.

${ }^{49}$ Mulder, Agama, Hidup Sehari-hari, 5.

50 "Setiap ideologi dan praktik agama dielaborasi, dipahami, dan direproduksi dalam tempat dan waktu tertentu". Dale F. Eickelman, "The Study of Islam in Local Context", dalam Richard C. Martin (ed.), Contributions to Asian Studies, Vol. 17 (Leiden: E.J. Brill, 1982), 1.
} 
Jawa, namun hal itu selalu dibentuk dalam konteks sejarah lokal. Much of the most characteristics Indic symbolism is visible, but always reworked in a fashion consistent with the popular bistory of the region. ${ }^{51}$ Dengan situs penelitian di wilayah Tengger, Hefner menemukan bahwa sebagian orang memang mengaku beragama Islam dan lainnya mengaku beragama Hindu atau Buddha, namun kedua kelompok ini tetap orang-orang Jawa yang terikat dengan roh leluhur, roh pelindung desa (danyang), menganjurkan pentingnya ritual komunal dan bersikap toleran dalam rangka menjaga harmoni sosial di antara mereka.

Lalu, apa sesungguhnya yang hendak dinyatakan dengan konsep lokalisasi ketika ia disodorkan sebagai alternatif dari sinkretisme? Jika konsep lokalisasi digunakan untuk menjelaskan tentang komunitas lokal sebagai active recipient dalam proses perjumpaan dengan budaya asing/luar yang memengaruhinya, maka ini sesungguhnya tidak menyangga apapun atas sinkretisme, karena tepat di pengertian inilah Geertz menggunakan istilah sinkretismenya. Memang, Mulder sendiri tidak menyoal sinkretisme sebagai fakta akulturasi sebagai konsekuensi logis dari pertemuan dua budaya. Dia hanya ingin memahami lebih dalam sesuatu yang mendasari sinkretisme. Konsep lokalisasi membantunya untuk lebih baik dalam memahami sinkretisme tanpa jatuh ke dalam nada penghinaan dan perendahan terhadap masyarakat lokal. ${ }^{52}$

Sementara, bagi kalangan yang menyodorkan Islam lokal sebagai "pasti Islam", mereka sesungguhnya mengingkari satu fakta penting bahwa banyak ritual yang dilakukan Muslim lokal masih ditopang oleh keyakinan-keyakinan pra-Islam. Kelompok ini boleh saja menyatakan bahwa proses Islamisasi (strategi adaptasionis) telah memasukkan roh Islam ke dalam praktik budaya lokal atau menyeleksi tradisi lokal berdasarkan prinsip-prinsip tauhid, namun ini sama sekali tidak berarti bahwa sinkretisme tidak terjadi. Inilah juga mengapa di kalangan kaum santri tradisional sendiri pun muncul tuduhan-tuduhan terhadap beberapa praktik Muslim lokal yang dianggap animistik atau tidak Islami.

Bagaimanapun juga, setiap perjumpaan dua tradisi pasti mengakibatkan adanya situasi saling memberi. Islam lokal tidak bisa mengelak dari situasi ini. Fakta inilah yang seringkali disebut dengan

\footnotetext{
51 "Sangat banyak dijumpai simbol-simbol agama India, tapi selalu diperlakukan sesuai dengan sejarah rakyat wilayah tersebut". Hefner, Hindu Javanese, 266.

52 Mulder, Agama, Hidup Sehari-hari, 4-5.
} 
istilah Islam sinkretis, di mana berbagai keyakinan diadopsi untuk diharmoniskan di dalam semangat Islam. Sesuai dengan tuntutan Islam normatif atau tidak, hal itu bukan menjadi kepentingan utamanya. Dalam pengertian ini, Islam lokal selalu diandaikan bersifat sinkretis, atau paling tidak adaptasionis. ${ }^{53}$

Dengan menggunakan pendekatan sosiologi interpretif Weber, akan berguna jika kita menggunakan konsep multivokalitas yang dikembangkan oleh Beatty. Konsep ini digunakan Beatty salah satunya untuk menjawab pertanyaan "Apa yang terjadi dengan Islam dan tradisi lokal atau dengan sinkretisme?".

Konsep multivokalitas merujuk pada praktik interplay antara interpretasi pribadi dan konstruksi publik mengenai ritual, atau mengenai manipulasi individual terhadap makna-makna simbolik. Konsep ini lahir dari kesadaran bahwa tidak ada yang disebut "fenomena sosial total", di samping kenyataan bahwa realitas sosial semakin divergen dan tersusun atas keragaman ideologi atau keyakinan. Konsep ini menekankan cara di mana individu-individu, dalam tatanan kebudayaan yang kompleks, menggunakan sumbersumber pengetahuan yang berbeda ketika memahami dan menafsirkan ritual..$^{54}$

Dalam penerapannya terhadap ritual slametan, Beatty menyatakan, Slametan adalah peristiwa komunal, tapi tidak mendefinisikan komunitas secara tegas; slametan berlangsung melalui ungkapan verbal yang panjang di mana semua orang setuju dengannya, akan tetapi hadirin secara perorangan belum tentu sepakat akan maknanya; dan, manakala upacara ini menyatukan semua orang dalam perspektif bersama mengenai manusia, Tuhan, dan dunia, maka upacara [selamatan] sesungguhnya tidak mewakili pandangan siapapun secara khusus. Ketimbang konsensus dan kesepakatan simbolik, kami menemukan kompromi dan sintesa sementara: yakni kesepakatan sementara di antara orang-orang yang sangat berbeda orientasinya. ${ }^{55}$

Di sini, penulis menggunakan konsep multivokalitas ini dalam memahami Islam Madura. Islam Madura bukanlah sebuah kategori yang solid. Ia tidak mencerminkan konsensus utuh yang merujuk pada

\footnotetext{
53 Ahmad Haris, "Innovation and Tradition in Islam: A Study on Bid'ah as an Interpretation of the Religion in the Indonesian Experience" (Disertasi--Tempel University Jepang, 1998), 35.

${ }^{54}$ Beatty, Variasi Agama Jawa, 37.

${ }^{55}$ Ibid., 36.
} 
satu fenomena sosial tunggal. Apa yang disebut sebagai Islam Madura adalah sebuah titik temu tanpa mengandaikan adanya konsensus. Seperti dalam sebuah kenduri di mana masing-masing individu dengan orientasi ideologi yang beragam membangun maknanya sendiri-sendiri atas apa yang terjadi, Islam Madura juga ditenun oleh beragam makna oleh masing-masing individu atau kelompok. Islam Madura bisa mewujud dalam satu praktik yang sama di mana masingmasing kelompok berpartisipasi di dalamnya, namun saat itu pula setiap kelompok terbuka untuk memberi makna untuk dirinya sendiri.

Proses Islamisasi atas orang Madura tidak bisa dipahami sebagai proses searah. Masyarakat Madura, sebagaimana setiap komunitas budaya, bukanlah penerima pasif dalam proses ini. Penerimaan Islam beserta dengan berbagai tuntutannya diambil, tapi kemudian diolah dan dimaknai kemudian dilahirkan kembali berdasarkan kekayaan spiritual yang mereka miliki.

Kaum Muslim tradisional jelas menerima dan bahkan menganjurkan ziarah kubur dan mendoakan orang yang sudah meninggal. Lebih dari itu, pemujaan terhadap makam wali juga praktik yang diterima di komunitas ini. Kalangan santri tidak merasa ada problem teologis apapun dengan praktik ini karena dalam teologi Islam ada ajaran tentang hidup sesudah mati. Melalui ajaran ini, penduduk lokal yang sudah berganti menjadi Muslim tetap merasa nyaman dengan praktik pemujaan roh leluhur yang sudah menjadi bagian dari keyakinannya selama ini. Apakah ini Islamisasi ataukah lokalisasi? Masing-masing kelompok memiliki maknanya sendiri, sekalipun mereka berada dalam "ruang identitas" yang sama.

Pemberian sesajian kepada roh leluhur jelas tidak bisa diterima dari sudut pandang Islam noramtif. Islam memang menganjurkan untuk menghormati para leluhur, namun itu konsep sangat berbeda dengan pemberian sesaji. Yang dianjurkan Islam adalah doa kepada orang yang sudah meninggal. Ketika terjadi proses Islamisasi dengan seluruh tuntutannya, masyarakat lokal memiliki caranya untuk tetap mempertahankan dan membenarkan praktik ini. Ini bukan soal siapa memanipulasi siapa, tapi inilah praktik interplay, di mana masingmasing pihak terbuka untuk memberi makna dan menegosiasikannya.

Beberapa contoh di bawah akan memberi gambaran yang jelas praktik interplay dalam Islam Madura. Orang Madura biasa melakukan slametan saat pembuatan rumah baru. Dalam ritual ini, ada praktik pemberian sesaji kepada roh leluhur berupa tajbin sanapora (bubur lima 
warna). Pemberian sesaji kepada roh leluhur tidak hanya akan menghadapi serangan dari kelompok reformis-puritanis, tapi juga dari kalangan pesantren. Tapi, oleh masyarakat Madura, ritual ini disandarkan pada sosok Bindhara Saod, seorang tokoh penyebar Islam awal di wilayah Sumenep yang dihormati kaum santri tradisionalis. Dikisahkan bahwa ketika Bindhara Saod menikah dengan Ratu Sumenep, dia tidak boleh tidur bersama istrinya selama 41 hari. Jika dia melakukannya, maka dia akan meninggal seperti suami-suami sang ratu sebelumnya. Selama waktu itu, Bindhara Saod bertapa di Gua Payudan, Batuampar. Dalam pertapaannya itulah dia mendapat wasiat agar membuat tajbin sanapora dan diletakkan di empat sudut dan tengah keratonnya. ${ }^{56}$ Bukan masalah apakah kisah Bindhara Saod ini benar atau tidak, tapi inilah praktik negosiasi melalui pemaknaan ulang atas simbol-simbol Islam.

Cerita yang lain adalah ketika masyarakat lokal memercayai dewa bumi sebagai sumber kekuatan dan kesuburan utama. Kepercayaan akan dewa bumi ini dianggap sebagai rahim dari keyakinan adanya roh penunggu suatu tempat. Roh ini mewujud dalam kekuatan tetua desa, sehingga roh nenek moyang memiliki kekuatan karena bisa berkomunikasi dengan kekuatan bumi. ${ }^{57}$ Inilah yang kemudian membentuk keyakinan bahwa tanah sebagai ibu.

Jelas keyakinan ini tidak bisa diterima dari standar tauhid yang sangat dijaga oleh Islam. Masyarakat lokal yang merasa terancam kemudian mengembangkan sebuah cerita bahwa ketika Nabi Muhammad melakukan isrä' mi'räj, ada seorang perempuan tua cantik yang memanggil namanya dan minta agar tidak ditinggalkan. Ketika Nabi bertanya kepada Jibril tentang perempuan itu, Jibril menjawab bahwa perempuan itu adalah ibunya, yaitu bumi. Dari bumilah manusia mendapatkan sumber kehidupannya. Menghormati bumi berarti menghormati ibunya. Ketika Islam mengatakan bahwa semua manusia terlahir dari Adam, maka Adam juga dimaknai sebagai tanah, dan tanah adalah ibu. Adam sebagai ibu karena wanita juga berasal darinya. ${ }^{58}$ Simbolisasi bumi dengan ibu jelas berasal dari Hindu

56 Bambang Samsu, "Rumah, Tanah, dan Leluhur di Madura Timur", dalam Soegianto (ed.), Kepercayaan, Magi, dan Tradisi dalam Masyarakat Madura (Jember: Tapal Kuda, 2004), 86-87.

57 Dominikus Rato, “Buju', dan Asta: Persepsi Masyarakat Madura Sumenep terhadap Kuburan Keramat”, dalam Soegianto (ed.), Kepercayaan, Magi, dan Tradisi dalam Masyarakat Madura (Jember: Tapal Kuda, 2004), 99.

58 Ibid., 134. 
terutama dalam cerita Ganeca yang memenangkan perlombaan dengan saudaranya mengelilingi bumi. Ganeca menjadi pemenang karena dia cukup mengelilingi ibunya. Ibu adalah bumi dan tanah.

Islam Madura adalah Islam yang maknanya ditenun oleh Muslim santri, le' kolek', dan onggu'. Mereka tidak selalu menemukan konsensus dalam maknanya. Ketika mereka berpartisipasi ke dalam apa yang disebut Islam Madura, mereka berbagi dalam ruang identitas yang sama. Muslim santri mungkin akan memberi makna lebih ortodoks atas Islam Madura, yang lain menempatkan konsep-konsep Islam dalam kosmologi lokal, yang lain lagi mungkin akan mengonstruksi makna-makna universal atas berbagai simbol-simbol Islam yang mereka miliki bersama. Tidak ada pilahan tegas di antara setiap kelompok karena masing-masing juga mengandaikan heterogenitas. Muslim santri setidaknya terpilah menjadi dua: tradisionalis dan reformis. Setiap kelompok memiliki gradasi jika diukur dari skala ketaatan terhadap tuntutan Islam normatif. Karena proses negosiasi berkembang terus, maka Islam Madura juga terus berkembang. Posisi masing-masing individu tidak pernah bersifat statis. Kelompok yang mengidentifikasi sebagai santri juga adalah mereka yang berada dalam kapal kebudayaan yang sama.

Dengan mengadaptasi penjelasan Beatty, penulis ingin meringkas Islam Madura sebagai berikut: Islam Madura adalah sebuah identitas komunal, tapi tidak mendefinisikan komunitas secara tegas. Islam Madura adalah sebuah identitas bersama yang disetujui oleh setiap Muslim yang berpatisipasi di dalamnya, akan tetapi secara perorangan atau kelompok atau sub-kelompok belum tentu sepakat akan maknanya. Islam ini menyatukan semua orang Madura dalam perspektif bersama mengenai manusia, Tuhan, dan dunia, tapi identitas ini sesungguhnya tidak mewakili pandangan siapapun secara khusus. Alih-alih konsensus, yang terjadi adalah kompromi dan sintesis sementara.

\section{Catatan Akhir}

Setiap perjumpaan dua tradisi pasti mengakibatkan adanya situasi saling memberi. Islam lokal tidak bisa mengelak dari situasi ini. Beatty menyodorkan konsep multivokalitas, yaitu praktik interplay antara interpretasi pribadi dan konstruksi publik mengenai ritual, atau mengenai manipulasi individual terhadap makna-makna simbolik. Konsep ini lahir dari kesadaran bahwa tidak ada yang disebut 
"fenomena sosial total", di samping kenyataan bahwa realitas sosial semakin divergen dan tersusun atas keragaman ideologi atau keyakinan. Konsep ini menekankan cara di mana individu-individu, dalam tatanan kebudayaan yang kompleks, menggunakan sumbersumber pengetahuan yang berbeda ketika memahami dan menafsirkan ritual..$^{59}$

Islam Madura bukanlah sebuah kategori yang solid. Ia tidak mencerminkan konsensus utuh yang merujuk pada satu fenomena sosial tunggal. Apa yang disebut sebagai Islam Madura adalah sebuah titik temu tanpa mengandaikan adanya konsensus. Seperti dalam sebuah kenduri di mana masing-masing individu dengan orientasi ideologi yang beragam membangun maknanya sendiri-sendiri atas apa yang terjadi, Islam Madura juga ditenun oleh beragam makna oleh masing-masing individu atau kelompok. Islam Madura bisa mewujud dalam satu praktik yang sama di mana masing-masing kelompok berpartisipasi di dalamnya, namun saat itu pula setiap kelompok terbuka untuk memberi makna untuk dirinya sendiri.

Proses Islamisasi atas orang Madura tidak bisa dipahami sebagai proses searah. Masyarakat Madura, sebagaimana setiap komunitas budaya, bukanlah penerima pasif dalam proses ini. Penerimaan Islam beserta dengan berbagai tuntutannya diambil, tapi kemudian diolah dan dimaknai kemudian dilahirkan kembali berdasarkan kekayaan spiritual yang mereka miliki.

Islam Madura adalah sebuah identitas komunal, tapi tidak mendefinisikan komunitas secara tegas. Islam Madura adalah sebuah identitas bersama yang disetujui oleh setiap Muslim yang berpartisipasi di dalamnya, akan tetapi secara perorangan atau kelompok atau sub-kelompok belum tentu sepakat akan maknanya. Islam ini menyatukan semua orang Madura dalam perspektif bersama mengenai manusia, Tuhan, dan dunia, tapi identitas ini sesungguhnya tidak mewakili pandangan siapapun secara khusus. Alih-alih konsensus, yang terjadi adalah kompromi dan sintesis sementara.

\section{Daftar Rujukan}

AG., Muhaimin. Islam dalam Bingkai Budaya Lokal: Potret dari Cirebon. Jakarta: Logos, 2001.

Azra, Azyumardi. Jaringan Ulama Timur Tengah dan Kepulauan Nusantara Abad XVII dan XVIII. Jakarta: Kencana, 2013.

${ }^{59}$ Beatty, Variasi Agama Jawa, 37. 
Beatty, Andrew. Variasi Agama Jawa: Suatu Pendekatan Antropologi, terj. Achmad Fedyani Saefuddin. Jakarta: Murai Kencana, 2001.

Bouvier, Helene. Lebur! Seni Musik dan Pertunjukan dalam Masyarakat Madura, terj. Rahayu S. Hidayat dan Jean Couteau. Jakarta: Forum Jakarta-Paris, Ecole Francaise d'Extreme-Orient, Yayasan Asosiasi Tradisi Lisan, Yayasan Obor Indonesia, 2002.

Budiwanti, Erni. Islam Sasak. Yogyakarta: LKiS, 2000.

Eickelman, Dale F. "The Study of Islam in Local Context", dalam Richard C. Martin (ed.), Contributions to Asian Studies, Vol. 17. Leiden: E.J. Brill, 1982.

Geertz, Clifford. The Religion of Java. Chicago dan London: The University of Chicago Press, 1960.

Graff, H.J. De. Puncak Kekuasaan Mataram. Jakarta: Grafiti, 2002.

Haris, Ahmad. "Innovation and Tradition in Islam: A Study on Bid'ah as an Interpretation of the Religion in the Indonesian Experience". Disertasi--Tempel University Jepang, 1998.

Hefner, Robert W. Hindu Javanese. Princeton, New Jersey: Princeton University Press, 1985.

Jonge, Huub de. "Kata Pengantar", dalam A. Latief Wiyata, Carok: Konflik Kekerasan dan Harga Diri Orang Madura. Yogyakarta: LKiS, 2006.

Jordaan, Roy Edward. Folk Medicine in Madura (Indonesia). Leiden: Leiden University, 1985.

Kodiran. "Kebudayaan Jawa", dalam Koentjaraningrat (ed.), Manusia dan Kebudayaan di Indonesia. Jakarta: Djambatan 2007.

Kuntowijoyo. Perubahan Sosial dalam Masyarakat Agraris Madura 18501940. Yogyakarta: Mata Bangsa, 2002.

Lombard, Denys. Nusa Jawa: Silang Budaya, Vol. 2. Jakarta: Gramedia, 1996.

Manger, Leif. "Muslim Diversity: Local Islam in Global Contexts", dalam Leif Manger (ed.), Muslim Diversity Local Islam in Global Contexts. Richmond: Curzon Press, 1999.

Mansurnoor, Iik Arifin. Islam in an Indonesian World: Ulama of Madura. Yogyakarta: Gadjah Mada University Press, 1990.

Mulder, Niels. Agama, Hidup Sehari-hari, dan Perubahan Budaya, terj. Satrio Widiatmoko. Jakarta: Gramedia, 1999), 10.

Niehof, Anke. Women and Fertility in Madura. Leiden: t.tp., 1985.

Pemberton, John. Jawa, terj. Hartono Hadikusumo. Yogyakarta: Mata Bangsa, 2003. 
Pranowo, Bambang. "Traditional Islam in Contemporary Rural Java", dalam M.C. Ricklefs (ed.), Islam in the Indonesian Social Context. Clayton, Victoria, Australia: Center of Southeast Asian Studies Monash University, 1991.

Rato, Dominikus. "Buju', dan Asta: Persepsi Masyarakat Madura Sumenep terhadap Kuburan Keramat", dalam Soegianto (ed.), Kepercayaan, Magi, dan Tradisi dalam Masyarakat Madura. Jember: Tapal Kuda, 2004.

Samsu, Bambang. "Rumah, Tanah, dan Leluhur di Madura Timur", dalam Soegianto (ed.), Kepercayaan, Magi, dan Tradisi dalam Masyarakat Madura. Jember: Tapal Kuda, 2004).

Soehadha, M. Orang Jawa Memaknai Agama. Yogyakarta: Kreasi Wacana, 2008.

Subaharianto, Andang. et al., Tantangan Industrialisasi Madura. Malang: Bayumedia, 2004.

Suryadinata, Leo dkk. Penduduk Indonesia: Etnis dan Agama dalam Era Perubahan Politik. Jakarta: LP3ES, 2003.

Vlekke, Bernard H. M. Nusantara Sejarah Indonesia, terj. Samsudin Berlian. Jakarta: Gramedia dan Freedom Institute, 2008.

Wiyata, A. Latief. Carok: Konflik Kekerasan dan Harga Diri Orang Madura. Yogyakarta: LKiS, 2006.

-----. Mencari Madura. Jakarta: Bidik Phronesis, 2013.

Woodward, Mark R. Islam Jawa: Kesalehan Normatif versus Kebatinan, terj. Hairus Salim HS. Yogyakarta: LKiS, 2004. 